\title{
Factors affecting the response of steel columns to close-in detonations
}

\author{
F. Dinu ${ }^{a}$, I. Marginean ${ }^{a *}$, D. Dubina ${ }^{a}$, A. Khalil ${ }^{b}$ and E. De Iuliis ${ }^{b}$ \\ ${ }^{a}$ Department of Steel Structures and Structural Mechanics, Politehnica University Timisoara, 300224, Romania \\ ${ }^{\mathrm{b}}$ Applied Science International, LLC, Durham, NC 27704, USA \\ *corresponding author, e-mail address: ioan.marginean@upt.ro
}

\begin{abstract}
Explosions produced in urban areas by the detonation of explosives are low-probability but high-impact events. When they occur in the immediate vicinity of buildings, the explosions can pose a high risk to the structural integrity (local/global failures) and to the occupants (risk of injury, death). Therefore, the design and the construction of the buildings should contain preventive measures to increase the robustness of the structures. The paper presents the results of recent research carried out on the safety of building structures under extreme actions. Blast tests performed on two identical 3D specimen extracted from a typical moment resisting steel frame structure, allow to calibrate the numerical models of a full scale building structural frame system and evaluate the consequences of close-in detonations on the structural elements. The data of the experimental testing, combined with the numerical modelling, allow to investigate different factors, such as dynamic factors that affect the local failure mechanism and the residual capacity of steel columns under different blast scenarios.
\end{abstract}

Keywords: Robustness; progressive collapse; blast wave; overpressure; moment resisting frames.

\section{Introduction}

During their designed lifetime, multi-story frame buildings may be subjected to extreme events, such as detonation of highly explosive materials in their close proximity. As the blast pressure decays exponentially with the distance from the charge, providing an adequate stand-off will substantially reduce the exposure of the building and the damage to the structural elements. Enhancing the local strength of building components to resist failure and creating alternate load paths are other means to reduce the vulnerability and prevent the progressive collapse of buildings, which is the main cause of blast related injuries and fatalities. Therefore, the awareness of such risk requires appropriate measures in the design and construction of buildings [1]. The ability of a structure to withstand extreme loading events without being damaged to an extent disproportionate to the original cause is called structural robustness [2]. Due to the complexity of the blast event (e.g. blast pressure distribution and history, dynamic effects in the structural materials), models and calculations need be checked against experimental data from tests on similar structures in order to provide a certain degree of accuracy. Reviews of the international research on structural robustness [3, 4] highlighted this need for more testing data and improved modelling and design guidance. Some contributions to the development of robustness provisions have been also obtained within past research projects COST TU0601 (2007-2011), COST C26 (2006-2010), ADBLAST (20102013), CODEC (2012-2016). Krishnappa et al. [5] conducted experimental testing and finiteelement simulation on wide flange propped cantilever columns to observe the deformation and failure modes when high explosives are detonated in the close proximity and load the column perpendicular to the weak axis of bending. Studies reported in $[6,7]$ also investigated the behavior of structures under blast loads. However, the difficulties and risk in 
developing real blast tests transferred most of the research to column loss tests (or similar) under static or dynamic conditions [8-12].

The paper presents the results of recent research carried out on the safety of building structures under extreme actions. A two-bay, two-span, and two-story steel frame building model was numerically tested for different blast loading conditions to evaluate the consequences of close-in detonations on the structural elements. The blast tests performed on two identical 3D specimens extracted from a typical moment resisting steel frame structure [12], allowed to calibrate the numerical models used in the analyses. The data of the experimental testing, combined with the numerical modelling, allow to investigate different factors, such as dynamic factors that affect the local failure mechanism, the residual capacity of steel columns under different blast scenarios and the potential for progressive collapse resulting from such extreme loading. The study is part of FRAMEBLAST research project, which aims at providing the validation of the response of a full scale building structural frame system under blast loading, see Fig. 1. The building will be subjected to blasts with different charge sizes and locations.

\section{Description of steel frame model}

The steel frame model has two bays, two spans, and two stories (Fig. 2.a). The bays and spans measure $4.5 \mathrm{~m}$ and $3.0 \mathrm{~m}$, respectively, while stories are $2.5 \mathrm{~m}$ high each. The structural system is made of moment resisting frames on the $\mathrm{x}$ direction, while on the $\mathrm{y}$ direction concentrically braces are introduced on the perimeter frames. The secondary beams are spaced at $1.5 \mathrm{~m}$ intervals. The extended endplate bolted beam-to-column connections in the moment resisting frames are designed as fully rigid and fully restrained connections (Fig. 2.b). Secondary beam-to-column connections and secondary beam-to-main beam connections are pinned (Fig. 2.c and Fig. 2.d). The column bases are welded to steel plates bolted to reinforced concrete girders, that constitute the foundations of the structure. These connections are fully rigid and restrained.The design of the structure was done considering the seismic design condition, combining the permanent actions (dead load D $=5 \mathrm{kN} / \mathrm{m}^{2}$ ), the variable actions (live load $\mathrm{L}=4$ $\mathrm{kN} / \mathrm{m}^{2}$ ) and the seismic action (low seismicity, horizontal acceleration $=0.10 \mathrm{~g}$ ). Horizontal and vertical tying requirements for accidental design situation were also verified using [2] provisions.

The design resulted in HEB260 columns, IPE270 sections for main beams, IPE200 for secondary beams between columns, and IPE160 for intermediate secondary beams. Note that structural steel in beams, columns, and plates is S275 (yield strength of $275 \mathrm{~N} / \mathrm{mm}^{2}$ ) and bolts are class 10.9 (ultimate strength of $1000 \mathrm{~N} / \mathrm{mm}^{2}$ ).

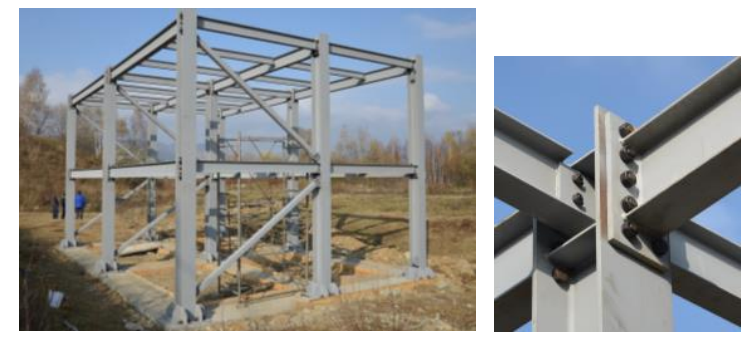

Fig. 1. Full scale building structural frame system to be tested under blast loading.

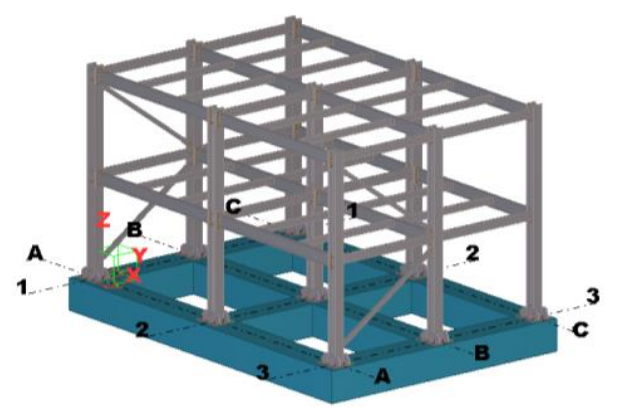

a)

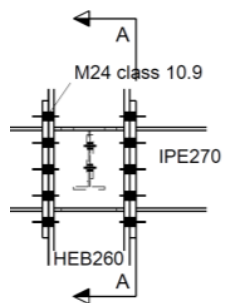

b)

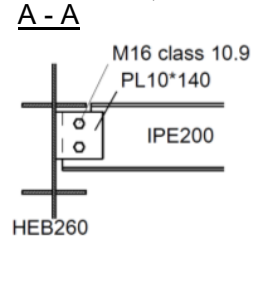

c)

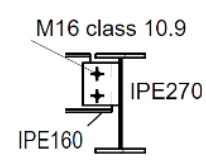

d)
Fig. 2. a) 3D view of the frame bulding; b) beam-tocolumn connection; c) secondary beam-to-column connection; d) secondary beam-to-main beam connection.

\section{Progressive collapse resistance of frame structures}

Notional column removal is largely used to describe the progressive collapse resistance of frame structures under accidental actions [1,2]. The procedure can assess the behavior of a frame structure in case of accidental loading by considering complete removal of key member, i.e. column, regardless of the initial cause of the damage (e.g. blast). Since the focus of the study is the evaluation of the effects of close-in detonations against steel frames (i.e. local damage and progressive collapse potential), two 
types of analysis procedures were carried out.

First analysis set employs the Alternate Path (AP) method using both static and dynamic incremental analysis [1]. Thus, the first storey middle perimeter column located at the intersection of grid line A and grid line 2 (see Fig. 2.a) is eliminated and the response is evaluated.

For dynamic analysis, the analysis procedure is repeated for increased gravity loads (dead and live load) till the structure undergos progressive collapse. The assessment of progressive collapse using the AP method is in accordance with the UFC 4-023-03 guidelines [13].

For nonlinear static analysis, the gravity load on the bays immediately adjacent to the lost element and on all floors above is given by:

$G_{N}=D I F \times[1.2 D+0.5 L]$

where $G_{N}$ is the increased gravity load for nonlinear static analysis, D is the dead load, L is the live load, and DIF is the dynamic increase factor for accounting for the dynamic effects of the column loss.

The combined load on the areas of the floor away from the lost column is given by:

$G=[1.2 D+0.5 L]$

where $\mathrm{G}$ is the gravity load.

However, in order to directly evaluate the dynamic amplification for each gravity load level, no amplification was applied in the static analysis.

For nonlinear dynamic analysis, the gravity load on the entire structure can also be calculated using eq. (2). The analysis cases are denoted as CR-S (for static analysis) and CR-D (for dynamic analysis), see Table 1.

The second type of analysis set consists is an explicit blast analysis, where the column is left in place and blast pressure is applied to the structure. The point of detonation is in the exterior of the structure, in the close proximity of same column A2. Column removal approach can provide an accurate prediction of the structure response when a column is severely damaged due to an accidental action. However, as seen from previous studies [12], in case of close-in detonations, the resistance to collapse of steel building frames depends very much on the blast load parameters (e.g. distance, weight), the level of gravity loads (compressive axial forces in columns), and the initial design conditions (seismic, non-seismic). As reported by [12], a charge weight $\mathrm{W}=1.815 \mathrm{~kg}$ placed at a standoff distance $\mathrm{R}=0.50 \mathrm{~m}$ from a steel column web caused little plastic deformations, while for same charge weight but smaller distance $(\mathrm{R}=0.20 \mathrm{~m})$, the web was completely removed on a length of almost twice the width. If compressive forces in the column were sufficiently high, the "free" flanges buckle and the column failed completely. As presented in FEMA 453 (2006), expanding blast wave causes, in sequence of events, the building envelope to fail, the internal upward lift on the floor slabs, and eventually the engulfment of the entire building. Jahromi and Izzudin [14] discovered that upward lift of beams due to direct blast pressure increases the dynamic increase factor, with regards to column removal. Therefore, in order to assess the blast loading effects and the potential for progressive collapse of steel frame buildings, the following parameters were considered in the blast analysis:

a) Charge weight (W) and stand-off distance (R) (see Table 1). $\mathrm{R}$ is defined as the distance from the center of the charge to the face of the column $A 2$. Both $R$ and $W$ are varied but the scaled distance, $Z$ (see eq. 3), remains constant:

$Z=R /\left(W^{1 / 3}\right)$

where $\mathrm{Z}$ is the scaled distance, in $\mathrm{m} / \mathrm{kg}^{1 / 3}, \mathrm{R}$ is in $\mathrm{m}$, and $\mathrm{W}$ is in $\mathrm{kg}$ TNT. Equation 3 is the blast scaling law introduced by Hopkinson [15] which establishes that similar explosive waves are produced at identical scaled distances when two different charges of the same explosive and with the same geometry are detonated in the same atmosphere. Thus, any distance $\mathrm{R}$ from an explosive charge $\mathrm{W}$ can be transformed into a characteristic scaled distance $\mathrm{Z}$.

b) Position above the ground at which the blast occurs. This is set at five different heights, see Table 1.

c) Different levels of gravity loads on the floors, which were considered by means of the factor $\lambda$, applied to the gravity load on the floors (increased until collapse is attained).

For the analysis, the pressure was modelled using automated blast pressure loading curves from UFC 3-340-02 [16], see Fig. 3. Only the positive phase of the blast wave was considered. The combined load on the areas of the floors was given by eq. (2), multiplied by $\lambda$ factor for each level of gravity load, see section 5 . From the 
combination of the parameters presented in Table 1, resulted a total of 60 different analysis cases. Each case is denoted by a combination of charge weight $\mathrm{W}$ at distance $\mathrm{R}$, height from the ground $\mathrm{H}$, and gravity load factor, $\lambda$. For all cases, the prefix is Ex.

Table 1. Nonlinear analysis study parameters.

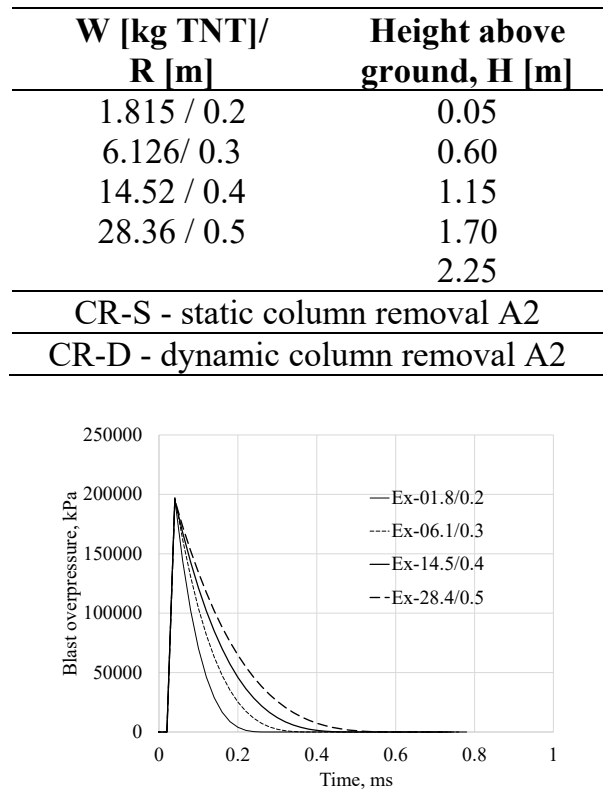

Fig. 3. Blast overpressure at the column face vs time for each pair of explozive weight/stand-off distance (only positive phase was considered).

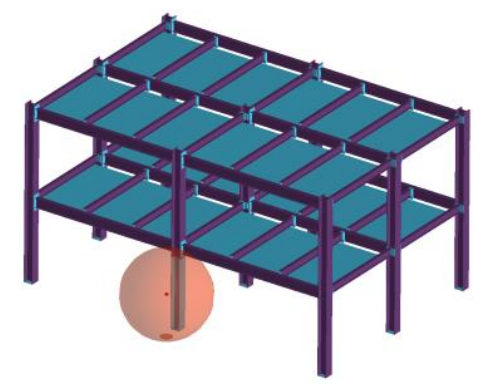

Fig. 4. Geometry of 3D numerical model and the representation of the blast in ELS.

\section{Numerical modeling}

The numerical analyses were performed using Extreme Loading for Structures (ELS) software, which employs a nonlinear solver based on the applied element method [17]. The calibration of the model was done using relevant blast test results on two identical 3D specimen extracted from a typical moment resisting steel frame structure [12]. The 3D geometrical model of the specimen, see Fig. 4 was constructed as an assembly of small (discrete) elements, connected by springs which are generated at contact points distributed around the element's mutual surfaces, paired as one normal and respectively two perpendicular shear springs. These springs can be removed when strain values reach the separation strain, or can be generated when contact occurs between elements, thus resulting in the modelling element separation and collision. The material models were defined by their main characteristics, i.e. elastic properties, yield strength, ultimate strength, maximum allowable elongation, and separation elongation. Structural steel S275 was assigned for all steel elements (beams, columns, plates) and class 10.9 bolts were used for connections.

Floor panels with no membrane or flexural resistance were used to model the transfer of the blast preassure (uplift) due to blast to the beams directly hit by the blast wave, see Fig. 4. In column removal scenarios, the presence of these panels have no influence on the capacity of the structure. To take into account the inertial effects, dead and live loads on the floors were introduced using lumped mass assigments on the top of the main and secondary beams. In the blast analsysis, a $2 \mathrm{~mm}$ bow imperfection (L/1250) was imposed on the strong axis of the column A2 from the first story.

\section{Results}

Fig. 5 compares the static and dynamic loaddisplacement curves of the structure when the first storey column A2 is removed,obtained by plotting the vertical displacement of a reference point (beam-column joint at first floor above the removed column) and the corresponding load factor $\lambda$. The static curve reports the vertical displacement and corresponding gravity load factor, $\lambda$, from initial stage till complete failure. The dynamic analysis curve represent the envelope of the maximum vertical displacements from the displacement-time histories under different floor loads.

As seen from Fig. 5, the gravity load factor corresponding to the ultimate load-carrying capacity for CR-D is $\lambda_{u}=2.75$. It is therefore of interest to compare the dynamic response of the structure calculated for the column removal scenario (CR-D) and direct blast analysis for gravity load amplifiers $\lambda<\lambda_{\text {u. }}$. Considering the large computational time and effort, the blast analysis results are reported for three values of $\lambda$ only, i.e. 1.5, 2.0, and 2.5. Fig. 6 shows the displacement - time histories of the same target point for blast analysis cases under the three levels of floor loads. For comparison, the 
maximum static displacement and dynamic displacement - time history from column loss analyses for the same level of floor loads (CR-S and CR-D) are also displayed. For clarity, only the blast cases leading to displacements larger than column removal analysis are shown. For $\lambda=1.5$, the progressive collapse is prevented in all cases, and the most critical one is Ex28.04/0.5-1.70, wich leads to largest permanent vertical deflection. For $\lambda=2.0$, the progressive collapse is prevented in all but one cases, namely Ex-28.04/0.5-1.70, while for $\lambda=2.5,10$ out of 20 cases lead to progressive collapse. In the following, the main results are discussed and influence of the parameters considered in the study is detailed.

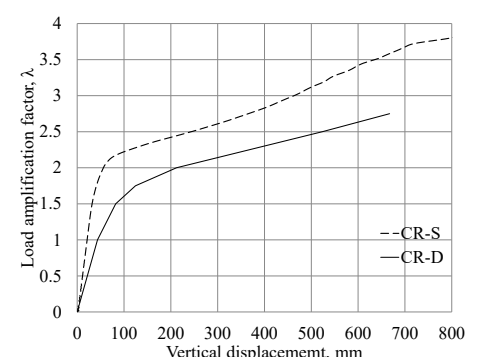

Fig. 5. Vertical force vs vertical displacement for CR-S and CR-D, column A2 removed.
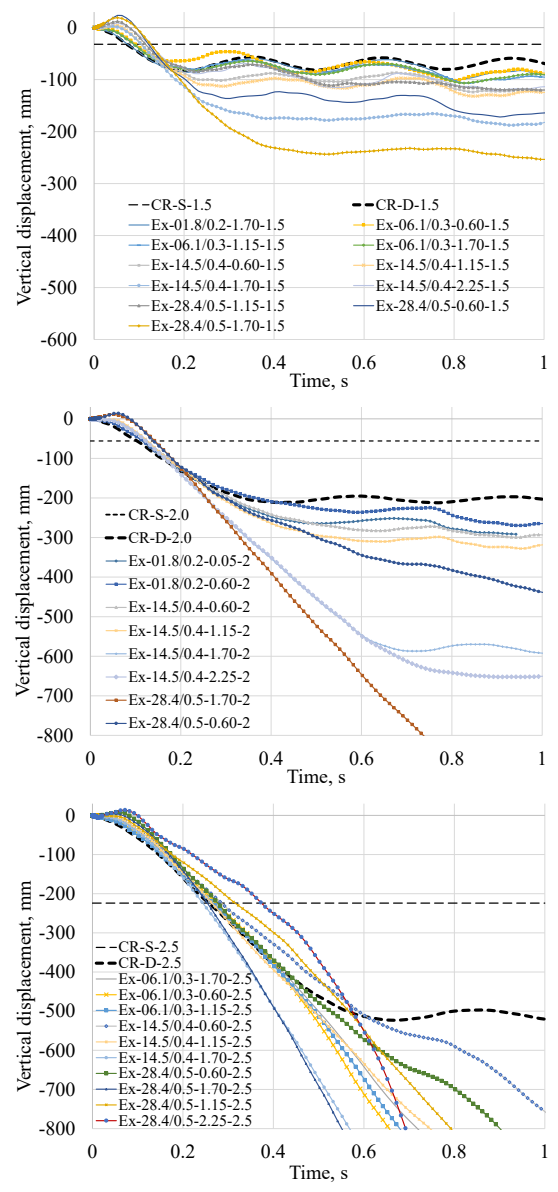

Fig. 6. Vertical displacement vs. time, Column A2, $\lambda=1.5,2.0,2.5$.

\subsection{Discussion on height of the blast above ground $(\mathrm{H})$}

The height $\mathrm{H}$ above ground of the explosive source was set at five different positions. The lowest position is just above ground level $(\mathrm{H}=0.05 \mathrm{~m})$, while the topmost was positioned just beneath the first storey main beams $(\mathrm{H}=2.25$ $\mathrm{m})$. This results in different loading situations for columns and floor beams. Note that no interaction of the blast wave with the ground was considered. Fig. 7 shows the displacement - time histories for blast analysis cases under two levels of floor loads ( $\lambda$ equal to 1.5 and 2.5) and two $\mathrm{W} / \mathrm{R}$ combinations (Ex-1.8/0.2 and Ex14.5/0.4).

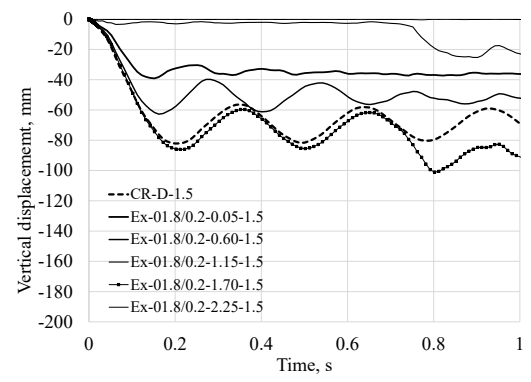

a) $\operatorname{Ex}-1.8 / 0.2, \lambda=1.5$

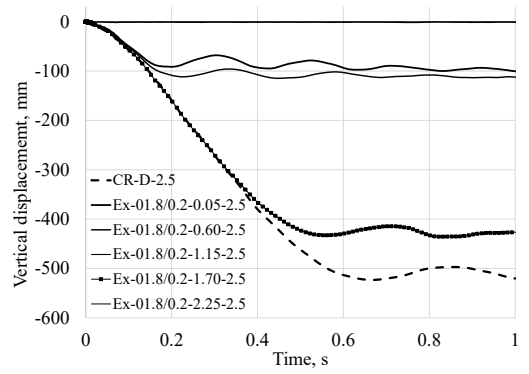

b) $\operatorname{Ex}-1.8 / 0.2, \lambda=2.5$

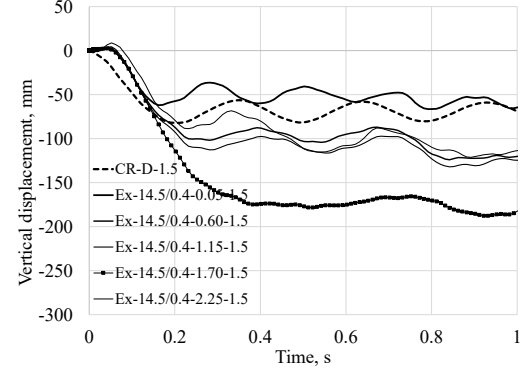

c) $\mathrm{Ex}-14.5 / 0.4, \lambda=1.5$

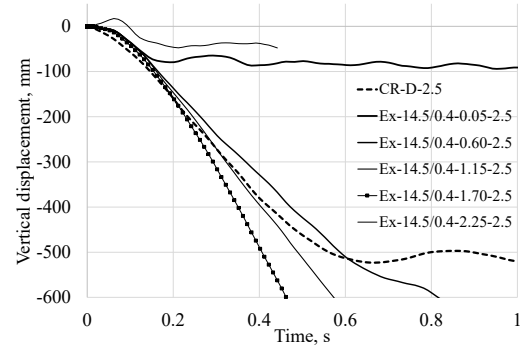

d) Ex-14.5/0.4, $\lambda=2.5$

Fig. 7. Column vertical displacement vs. time for different heights $\mathrm{H}$ above ground. 
Thus, for explosions that take place close to the ground, the column A2 is loaded locally, and, furthermore experienced the overpressures peaks in sections close to the fixed base joint and therefore, they can achieve a reduced horizontal displacement compared with the case where the overpressure peak hits the middle sections far away from the restrained joint. The result is a punching shear failure, prior to the development of any flexural deformations. The uplift pressure against $1^{\text {st }}$ floor varies and reaches the maximum for $\mathrm{H}=0.60 \mathrm{~m}$ (Fig. 8). From the combination of the two factors (i.e. initial local damage and uplift), the critical location for the detonation is in most cases at the top side of the first storey column $(\mathrm{H}=1.70 \mathrm{~m})$. In this case, beams and connections neighouring the columns are also damaged, and even the uplift pressure is not at the maximum (see Fig. 8), it still leads to additional dynamic effects, especially for larger blasts.

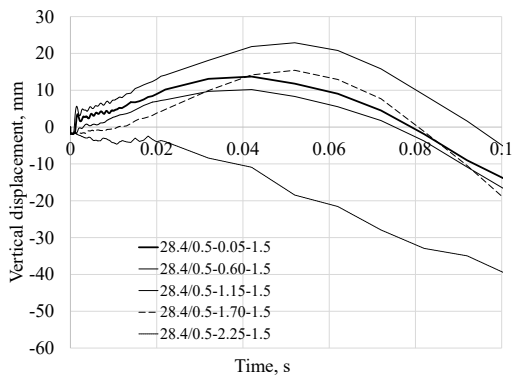

Fig. 8. Beams vertical displacement at $1^{\text {st }}$ floor vs. time for 28.4/0.5 case and different heights $\mathrm{H}$.

\subsection{Discussion on charge weight $(W)$ and stand-off distance $(R)$}

Each of the four combinations of W/R result in the same scaled distance, $Z=0.16 \mathrm{~m} / \mathrm{kg}^{1 / 3}$. However, the effects in terms of local damage (direct effects) and structural resistance against progressive collapse (indirect effects) are very different. This phenomenon can be attributed first to the additional damage in the other members of the structure, beyond the column, for larger explosive weights. As may be seen from Fig. 9, for Ex-01.8/0.2, the column is almost completely removed, while for Ex06.1/0.3 some local damage in the connection zone are produced.

For Ex-14.5/0.4 and Ex-28.4/0.5, the extent of damage is much greater and, apart from the column, which is completely destroyed, there are also damages in beams ends and their connections to the column. This effect may be also seen from Fig. 10, where the variation in time of weak axis shear force $V_{y}$ and bending moment $\mathrm{M}_{\mathrm{z}}$ in beam A1-2 (end 2) from $1^{\text {st }}$ floor is plotted for four different W/R blasts $(H=1.7$, $\lambda=1.5)$.
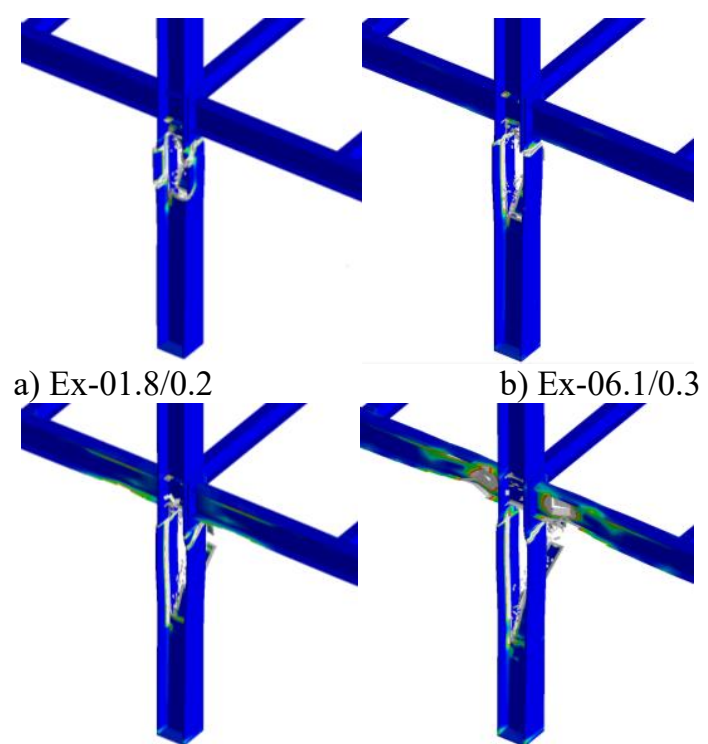

c) $\mathrm{Ex}-14.5 / 0.4$

d) $\mathrm{Ex}-28.4 / 0.5$

Fig. 9. Direct damage due to blast, charges at $\mathrm{H}=$ $1.7, \lambda=1.5$.

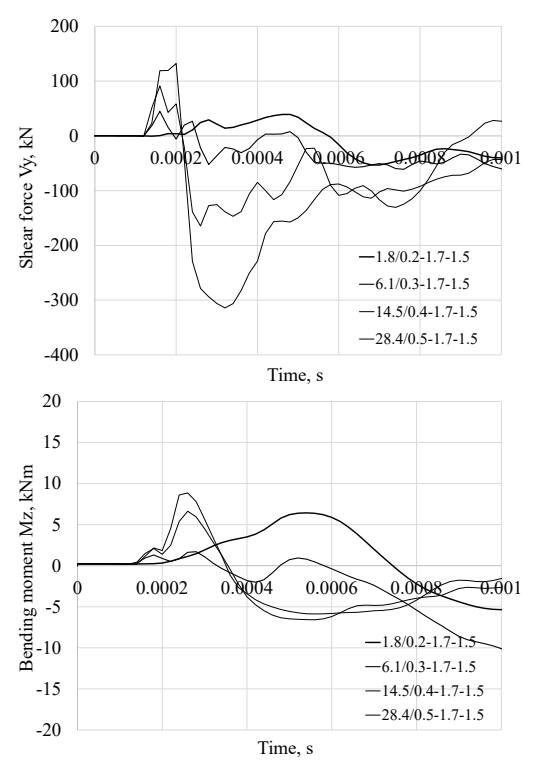

Fig. 10. Shear force $\mathrm{V}_{\mathrm{y}}$ and bending moment $\mathrm{M}_{\mathrm{z}}$ in beam $\mathrm{A} 1-2$ from $1^{\text {st }}$ floor vs. time, charges at $\mathrm{H}=$ $1.7, \lambda=1.5$.

Second important effect is the additional dynamic amplification caused by blast pressure, when beams are lift upward, especially in case of larger blast weights and lower gravity loads. Fig. 11 plots the vertical displacement time histories in the perimeter beams A1-2 first and second floor cross section end 2, for two W/R cases (28.4/0.5 and 1.8/0.2) and two heights $\mathrm{H}(0.6$ and 1.7 ), at $\lambda=1.5$. Only first 10 miliseconds are displayed. As may be seen, for large blast charge 
(Ex-28.4), the beams are subjected to uplift pressures, and the maximum displacement (uplift) are $22.8 \mathrm{~mm}$ and $17.6 \mathrm{~mm}$ at $1^{\text {st }}$ and $2^{\text {nd }}$ floor, respectively. For low charge weights (Ex1.8), there is no uplift and after the blast wave damages the column, the beams are deflecting only downwards. The variation in time of shear force $\mathrm{V}_{\mathrm{z}}$ and bending moment $\mathrm{M}_{\mathrm{y}}$ in beam A1-2 (end 2) from $1^{\text {st }}$ floor is plotted in Fig. 12 for four different $\mathrm{W} / \mathrm{R}$ blasts $(\mathrm{H}=1.7, \lambda=1.5)$. As may be seen, at the cross section analyzed, the uplift pressure determines a large increase of the strong axis bending and shear. Therefore, the effect of uplift requires that members that may be exposed to blast to be designed for load reversals. Seismic detailing are however designed for multiple cycles of load reversals and are generally well suited for these extreme loading conditions.

Fig. 13 shows the size of the floor areas that is likely to be affected by uplift due to blast. As may be seen, large parts of floors from the adjoining bays are subjected to uplift pressures.

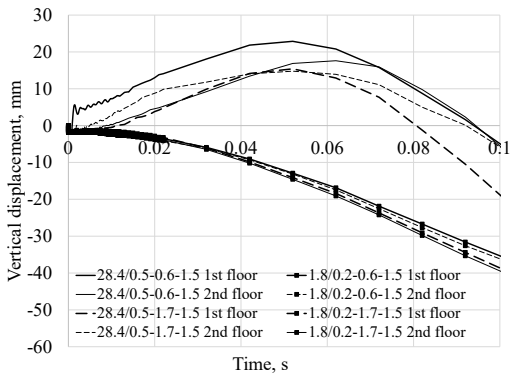

Fig. 11. Beams vertical displacement vs. time for two different $\mathrm{W} / \mathrm{R}$ cases and two different heights $\mathrm{H}$ above ground.

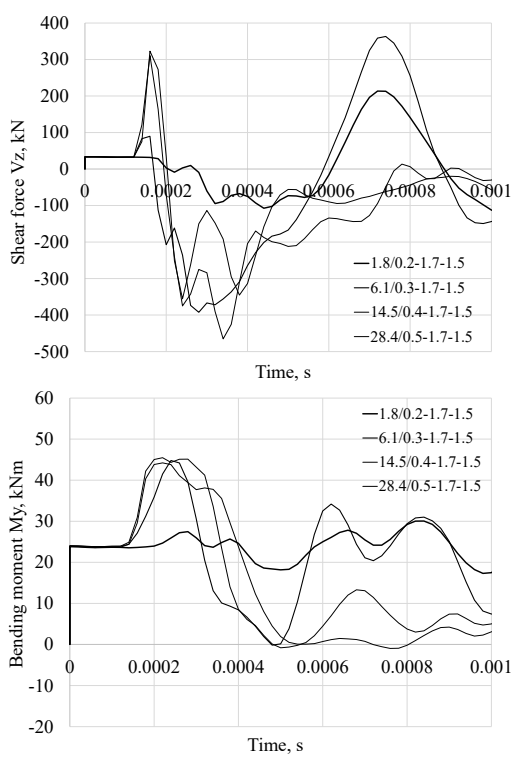

Fig. 12. Shear force $\mathrm{V}_{\mathrm{z}}$ and bending moment $\mathrm{M}_{\mathrm{y}}$ in beam $\mathrm{A} 1-2$ from $1^{\text {st }}$ floor vs. time, charges at $\mathrm{H}=$ $1.7, \lambda=1.5$.

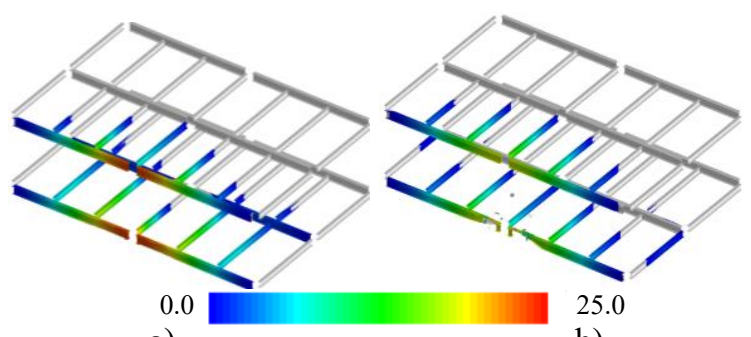

a)

b)

Fig. 13. Vertical displacement, in $\mathrm{mm}$ : a) Ex28.4/0.5-0.6-1.5; b) Ex28.4/0.5-1.7-1.5.

Both blast cases Ex-1.8/0.2 and Ex-6.1/0.3 are well approximated by notional column removal for $\lambda=1.5$ and 2.0, see Fig. 14 . However, as the blast charge increases (but scaled distance is kept constant by increasing the distance), the damages are larger and the progressive collapse resistance is exceeded for heavier gravity loads. For such cases, the application of APM does not result in conservative results.
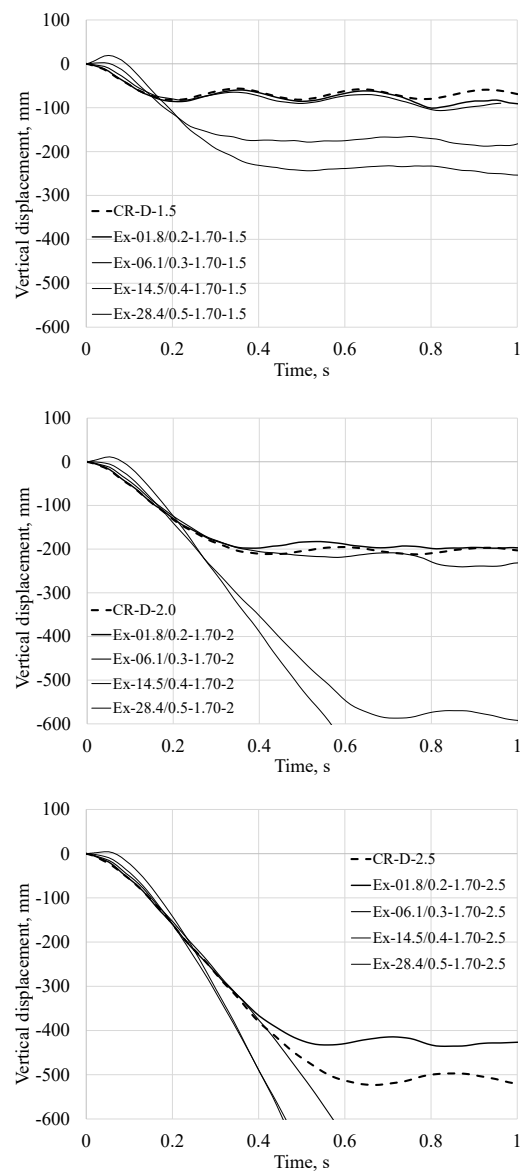

Fig. 14. Column vertical displacement vs. time for $\mathrm{H}=1.70 \mathrm{~m}, \lambda=1.5,2.0,2.5$.

\section{Conclusions}

Close-in detonations can result in the severe local damage of critical structural elements of 
buildings (e.g. vertical load carrying elements) even for small blast charges. The parametric numerical study showed that the local failure mechanism and the residual capacity of steel frames depend not only on the scaled distance $\mathrm{Z}$ but also on the size and position of the explosive charge. For small weights, even the local damage is severe (column completely removed), the structure has adequate capacity to resist the progressive collapse. The application of AP method based on notional column removal provides corservative results. However, for large weights (scaled distance kept constant), the direct damages (due to blast) can be much larger and involve more structural elements, thus can initiate the progressive collapse. The effect is amplified by the uplift pressure against the adjoining floors, which increases the dynamic effects and risk of progressive collapse. A research project, aiming to develop and validate numerical models for predicting the blast response of a steel framed building, is in progress. The building will be subjected to blasts with different charge sizes and locations, resulting in different scaled distances. As the scaled distance reduces, the peak overpressure increases, thus causing the shear failure of the elements located in the proximity. The potential for progressive collapse following local damage will be investigated.

\section{Acknowledgement}

This work was supported by a grant of the Romanian National Authority for Scientific Research and Innovation, CNCS/CCCDI UEFISCDI, project number PN-III-P2-2.1-PED2016-0962, within PNCDI III: "Experimental validation of the response of a full-scale frame building subjected to blast load" FRAMEBLAST (2017-2018).

\section{References}

[1] DoD. Unified facilities criteria: Design of buildings to resist progressive collapse. Washington (DC), US United States Department of Defense; 2016.

[2] CEN. Eurocode 1: Actions on structures - Part 17: Accidental actions Brussels European Committee for Standardisation; 2006.

[3] CPNI. Review of international research on structural robustness and disproportionate collapse London Department for Communities and Local Government 2011.
[4] El-Tawil S, Li H, Kunnath S. Computational Simulation of Gravity-Induced Progressive Collapse of Steel-Frame Buildings: Current Trends and Future Research Needs. Journal of Structural Engineering 2014;140:A2513001.

[5] Krishnappa N, Bruneau M, Warn GP. Weak-axis behavior of wide flange columns subjected to blast. Journal of Structural Engineering 2014;140:04013108.

[6] Fu F. Dynamic response and robustness of tall buildings under blast loading. Journal of Constructional Steel Research 2013;80:299-307.

[7] Mazurkiewicz L, Malachowski J, Baranowski P. Blast loading influence on load carrying capacity of I-column. Engineering Structures 2015;104:107-15.

[8] Fu QN, Tan KH, Zhou XH, Yang B. Loadresisting mechanisms of 3D composite floor systems under internal column-removal scenario. Engineering Structures 2017;148:357-72.

[9] Yang B, Tan KH, Xiong G, Nie SD. Experimental study about composite frames under an internal column-removal scenario. Journal of Constructional Steel Research 2016;121:341-51.

[10]Dinu F, Dubina D, Marginean I. Improving the structural robustness of multi-story steel-frame buildings. Structure and Infrastructure Engineering 2015;11:1028-41.

[11]Dinu F, Marginean I, Dubina D, Petran I. Experimental testing and numerical analysis of 3D steel frame system under column loss. Engineering Structures 2016;113:59-70.

[12]Dinu F, Marginean I, Dubina D. Experimental testing and numerical modelling of steel momentframe connections under column loss. Engineering Structures 2017;151:861-78.

[13]DoD. Unified facilities criteria: Structures to resist the effects of accidental explosions. Washington (DC), US United States Department of Defense; 2008.

[14]Zolghadr Jahromi H, Izzuddin B, Nethercot D, Donahue S, Hadjioannou M, Williamson E et al. Robustness Assessment of Building Structures under Explosion. Buildings 2012;2:497-518.

[15] Hopkinson B. British ordnance board minutes 13565. The National Archives, Kew, UK 1915:11.

[16] DoD. Unified facilities criteria: Structures to resist the effects of accidental explosions. Washington (DC), US United States Department of Defense; 2014.

[17] Tagel-Din H, Meguro K. Applied Element Method for simulation of nonlinear materials: theory and application for RC structures. Structural Eng/Earthquake Eng, JSCE 2000;17. 